\title{
PENGARUH KUALITAS PELAYANAN, HARGA DAN LOKASI TERHADAP KEPUASAN KONSUMEN \\ (Studi Kasus Pada Konsumen Paras Snack Di Kabupaten Boyolali Tahun 2019)
}

\author{
Fakultas Ekonomi Managemen \\ Universitas Boyolali \\ Jl. Pandanaran No. 405 Boyolali
}

Isnaini Sholikah $^{1)}$, Unna Ria Safitri ${ }^{2)}$, dan A.Fidhdiarr Ariestanto ${ }^{3)}$

e-mail: sholikah4889@gmail.com ${ }^{1)}$, unnaria68@gmail.com ${ }^{2)}$, kafidiar@yahoo.com ${ }^{3)}$

\begin{abstract}
ABSTRAK
Tujuan penelitian mengetahui pengaruh dari variabel harga, lokasi, serta kualitas pelayanan, terhadap kepuasan konsumen. 100 orang responden yang dijadikan sebagai sampel dilibatkan dalam pengisian kuesioner, diambil dari konsumen Paras Snack. Pengumpulan datanya menggunakan penyebaran kuesioner dengan metode responden yang kebetulan ditemui saat itu dan analisis dengan metode kuantitatif. Uji validitas dan reliabilitas digunakan dalam pengujian instrumen data, dan uji normalitas, uji multikolinearitas, uji heterokedastisitas, uji autokorelasi digunakan untuk menganalisis data, uji t dan uji $F$ serta uji determinasi $\left(\mathrm{R}^{2}\right)$ digunakan untuk uji hipotesisnya. Uji validitas, uji reliabilitas dan uji asumsi klasik yang datanya sudah terpenuhi kemudian diolah sehingga menghasilkan persamaan regresi : $\mathrm{Y}=4.475+0.126 \mathrm{X}_{1}+0.348 \mathrm{X}_{2}+0.374$. Secara parsial variabel kualitas pelayanan tidak mempengaruhi variabel kepuasan konsumen, sedangkan variabel yang berpengaruh terhadap kepuasan konsumen secara parsial yakni variabel harga dan lokasi yang ditunjukkan dengan pengujian hipotesis yakni menggunakan uji-t. Kemudian hasil dari uji $\mathrm{F}$ ditunjukkan secara simultan adanya pengaruh ketiga variabel independen terhadap variabel dependen. Disebutkan dari hasil uji determinasi $\left(\mathrm{R}^{2}\right)$ bahwa nilai dari Adjusted $R$ Square sebesar 0.811, yang artinya variabel dependen kepuasan konsumen dengan nilai sebesar $81.1 \%$ mampu dijelaskan oleh ketiga variabel independen yakni variabel harga, lokasi dan kualitas pelayanan dan nilai $18.9 \%$ sisanya dijelaskan oleh variabel diluar penelitian misalnya diskon, kualitas produk, fasilitas dan lain sebagainya.
\end{abstract}

Kata kunci : Kualitas Pelayanan, Harga, Lokasi dan Kepuasan Konsumen.

\begin{abstract}
The research objective is to determine the effect of price, location, and service quality variables on customer satisfaction. 100 respondents who were used as samples were involved in filling out the questionnaire, taken from Paras Snack consumers. Collecting data using questionnaires with the Accidential Sampling Method, and analysis using quantitative methods. The validity and reliability tests were used in the data instrument testing, and the normality test, multicollinearity test, heteroscedasticity test, autocorrelation test were used to analyze the data, the t test and $F$ test and the determination test $(R 2)$ were used to test the hypothesis. Validity test, reliability test and classical assumption test whose data have been met are then processed to produce a regression equation: $Y=$ $4,475+0.126 X 1+0.348 X 2+0.374$. Partially service quality variables do not affect customer satisfaction variables, while variables that affect customer satisfaction partially are price and location variables as indicated by hypothesis testing using the t-test. Then the results of the F test are shown simultaneously the influence of the three independent variables on the dependent variable. It is stated from the results of the determination test $(R 2)$ that the value of the Adjusted $R$ Square is 0.811 , which means that the dependent variable of customer satisfaction with a value of $81.1 \%$ can be explained by
\end{abstract}


the three independent variables, namely the variable price, location and service quality and the remaining $18.9 \%$ value is explained by the variable outside of research.

Keywords: Service Quality, Price, Location and Customer Satisfaction

\section{Pendahuluan}

Di Indonesia UMKM (Usaha Mikro Kecil dan Menengah) terlihat berkembang pesat, terlebih dalam usaha bidang kuliner. Ini dapat dilihat dari data UMKM Binaan di Jawa Tengah pada tahun 2015 tercatat sejumlah 108.937 anggota, tahun 2016 meningkat menjadi 115.751 anggota dan pada tahun 2017 menjadi 133.679 anggota. Salah satunya usaha di bidang makanan ringan (snack) merupakan usaha yang saat ini banyak diminati oleh para pelaku usaha. Banyak pelaku usaha, jenis makanan ringan berkompetisi menguasai pangsa pasar, seperti halnya Paras Snack yang mana memiliki strategi dan keunggulan yang berbeda dengan pelaku usaha sejenis. Kualitas pelayanan sangat menjadi hal penting bagi sebagian konsumen, karena akan berdampak pada kepuasan konsumen. Selain itu harga juga berpengaruh terhadap persepsi pelanggan terhadap produk. Apabila produk yang dijual sesuai dengan kemampuan beli masyarakat maka tidak menutup kemungkinan perputaran produk tersebut akan semakin cepat. Seperti halnya Paras Snack yang mematok harga yang dapat dijangkau oleh semua kalangan. Tidak kalah pentingnya lokasi yang mana menjadi pertimbangan konsumen dalam melakukan pembelian. Lokasi yang strategis, nyaman, aman dan dekat dengan keramaian biasanya menjadi daya tarik tersendiri karena akses yang mudah dijangkau, (Suminar 2017).

Sejak adanya pesaing usaha sejenis yang bermunculan, ada beberapa pedagang ritel yang memilih tempat lain sebagai tempat mereka mengambil dagangan. Cahaya Snack dan Dapur Aura merupakan pesaing Paras Snack yang juga berada di wilayah Boyolali dan menjual produk sejenis dengan Paras Snack. Hal itu menyebabkan kenaikan omset Paras Snack yang kurang signifikan di tahun 2019. Sehingga peneliti ingin mengetahui pengaruh variabel harga, lokasi, serta kualitas pelayanan, terhadap kepuasan konsumen. Sehingga kedepannya diharapkan hasil dari penelelitian ini dapat bermanfaat khususnya bagi pelaku usaha Paras Snack.

\section{Landasan Teori dan Pengembangan Hipotesis}

Tjiptono ( $2016: 59$ ) mengatakan bahwa kualitas pelayanan merupakan tingkat unggulan yang diharapkan dan pengendalian atas tingkat keunggulan tersebut untuk memenuhi keinginan pelanggan. Beberapa indikator kualitas pelayanan yang dituturkan Kotler dalam Fandy Tjiptono ( 2016 : 284 ) yakni, berwujud/nyata, empati, cepat tanggap, keandalan dan kepastian. Kajian penelitian Indra Firdiyansyah ( 2017 : 26 ) memaparkan bahwa secara parsial maupun secara simultan variabel kualitas pelayanan, harga dan lokasi berpengaruh terhadap kepuasan konsumen. Dari pernyataan diatas disimpulkan bahwa variabel kualitas pelayanan berpengaruh positif terhadap variabel kepuasan konsumen.

Philip Kotler ( 2012 : 132 ), menyebutkan bahwa harga merupakan sejumlah uang yang harus dibayarkan pelanggan untuk produk itu. Indikator harga menurut Kotler dan Amstrong ( $2011: 439$ ), yakni harga beserta kualitas produk cocok, price list sebagai pertimbangan konsumen, pemberian potongan harga khusus, tinggi rendahnya persepsi harga oleh konsumen. Hasil penelitian yang dilakukan oleh Muhammad Wahyudi (2018) bahwa secara parsial maupun simultan menunjukkan adanya pengaruh yang signifikan dari variabel harga, lokasi, suasana dan kualitas produk terhadap variabel kepuasan pelanggan. Sehingga disimpulkan penulis bahwa harga berpengaruh positif terhadap kepuasan konsumen. 
Tjiptono ( 2015 : 345 ), mengemukakan bahwa lokasi mengacu pada berbagai aktivitas pemasaran yang berusaha memperlancar dan mempermudah penyampaian atau penyaluran barang dan jasa dari produsen ke konsumen. Indikator lokasi yang dijabarkan Tjiptono dalam Kuswatiningsih ( 2016 : 15 ), yakni akses menuju lokasi, terlihat/nampak, lalu lintas ( Traffic ), lokasi parkir yang luas aman dan nyaman, ekspansi, lingkungan persaingan, ( lokasi pesaing ), peraturan pemerintah. Dari hasil penelitian Ahmad Mansyur Pane (2017) yang telah melakukan pengkajian secara simultan ( bersama-sama ) adanya pengaruh yang signifikan dari variabel kualitas layanan, fasilitas, harga, dan lokasi terhadap variabel kepuasan konsumen. Sehingga disimpulkan penulis bahwa lokasi berpengaruh positif terhadap variabel kepuasan konsumen.

Tjiptono ( $2015: 146$ ), menuturkan bahwa kepuasan konsumen adalah perasaan senang atau kecewa yang muncul setelah membandingkan persepsi terhadap kinerja (hasil) suatu produk dengan harapan-harapannya. Indikator kepuasan konsumen menurut Irawan dalam Lina Sari Situmaeng ( 2017 : 38 ), yakni merasa puas, selalu membeli produk (repeat order), akan merekomendasikan kepada orang lain, terpenuhinya harapan pelanggan setelah membeli produk.

\section{Metode Penelitian}

Metode yang digunakan dalam penelitian ini adalah penelitian kuantitatif. Peneliti menggunakan wawancara sebagai teknik pengumpulan data kepada pemilik Paras Snack, penyebaran angket yang berupa kuesioner kepada responden yang datanya akan diolah, dan studi dokumen dari pembukuan serta arsip foto Paras Snack.

"Populasi adalah wilayah generalisasi yang terdiri atas objek atau subjek yang mempunyai kuantitas dan karakteristik tertentu yang ditetapkan oleh peneliti untuk dipelajari kemudian ditarik kesimpulan", Sugiyono ( $2018: 130$ ). Populasi yang terlibat dalam penelitian adalah konsumen Paras Snack. Menurut Sugiyono ( $2017: 81$ ), "Sampel adalah bagian dari jumlah karakteristik yang dimiliki oleh populasi." Karena jumlah populasi Paras Snack tidak diketahui jumlahnya, maka perhitungan sampel menggunakan rumus yang dikemukakan oleh Wibisono dalam Anonym ( $2010: 31$ ) sebagai berikut :

$$
\begin{gathered}
n=\left(\frac{Z a / 2}{e}\right)^{2} \\
=\left(\frac{(1,96) \cdot(0,25)}{0,05}\right)^{2} \\
=96,04 \text { atau } 100 \text { sampel } \\
n \quad=\text { ukuran sampel } \quad \begin{array}{l}
\text { a } \\
Z a=05 \text { maka } Z 0,05=1,96
\end{array} \\
\sigma=\text { standar deviasi populasi } \\
e \quad=\text { tingkat kesalahan }
\end{gathered}
$$

Dari rumus diatas diperoleh sampel sebanyak 96 sampel, sehingga dibulatkan menjadi 100 sampel. Adapun teknik pengambilan sampel dengan non probability sampling methode, dengan menggunakan teknik accidental sampling yakni penentuan sampel berdasarkan konsumen yang bertemu secara tidak sengaja atau kebetulan yang dirasa cocok sebagai sumber data.

Objek penelitian ini dalam bidang pemasaran mengenai pengaruh lokasi, kualitas pelayanan serta harga, terhadap kepuasan konsumen produk Paras Snack. Penelitian ini dilaksanakan di Paras Snack (salah satu UMKM yang memproduksi makanan ringan khas Boyolali) yang beralamat di Desa Paras Wetan 03/01, Paras, Cepogo Boyolali. Penelitian deskriptif kuantitatif adalah upaya untuk memperoleh data secara lengkap dan akurat dari berbagai keadaan, kondisi dan situasi yang diteliti.

Kualitas Pelayanan $\left(\mathrm{X}_{1}\right)$ yaitu kualitas pelayanan terbaik yang diberikan Paras Snack kepada para konsumen sehingga konsumen akan merasakan kenyamanan dan menimbulkan rasa puas ketika mereka berbelanja di Paras Snack. Harga $\left(\mathrm{X}_{2}\right)$ merupakan keterjangkauan dan kesesuaian harga produk yang diberikan Paras Snack kepada konsumen untuk mempertimbangkan sebelum melakukan 
pembelian. Harga terjangkau, kualitas produk sesuai harapan memberikan rasa puas kepada konsumen. Lokasi $\left(\mathrm{X}_{3}\right)$ yaitu lokasi Paras Snack yang mudah dijangkau, bersih, rapi dan nyaman serta mempunyai tempat parkir yang luas dan keadaan dilokasi yang aman, memberikan penilaian tersendiri bagi para konsumen dalam menentukan kepuasan.

Analisis Deskriptif yaitu analisis yang digunakan untuk mendeskripsikan tentang variabel lokasi, kualitas pelayanan serta harga, terhadap kepuasan konsumen produk Paras Snack di Kabupaten Boyolali. Analisis regresi berganda digunakan untuk menerangkan sejauh mana pengaruh variabel lokasi, kualitas pelayanan serta harga, terhadap kepuasan konsumen produk Paras Snack di Kabupaten Boyolali. Data yang diperoleh akan diolah menggunakan program pengolah data komputer yaitu SPSS 22 untuk melihat hasil nilai koefisien determinasi yang lebih akurat.

\section{Hasil serta Pembahasan}

\subsection{Uji Instrumen Penelitian}

\section{Uji Validitas}

\section{Tabel 1}

Hasil Uji Validitas

\begin{tabular}{|c|c|c|c|c|}
\hline Variabel & Pernyataan & $\mathbf{r}_{\text {tabel }}$ & $\mathbf{r}_{\text {hitung }}$ & Ket \\
\hline \multirow{7}{*}{$\begin{array}{c}\text { Kualitas } \\
\text { Pelayanan } \\
\left(\mathrm{X}_{1}\right)\end{array}$} & Butir 1 & 0.197 & 0.874 & Valid \\
\hline & Butir 2 & 0.197 & 0.873 & Valid \\
\hline & Butir 3 & 0.197 & 0.907 & Valid \\
\hline & Butir 4 & 0.197 & 0.893 & Valid \\
\hline & Butir 5 & 0.197 & 0.923 & Valid \\
\hline & Butir 6 & 0.197 & 0.875 & Valid \\
\hline & Butir 7 & 0.197 & 0.947 & Valid \\
\hline \multirow{7}{*}{$\begin{array}{l}\text { Harga } \\
\left(\mathrm{X}_{2}\right)\end{array}$} & Butir 1 & 0.197 & 0.826 & Valid \\
\hline & Butir 2 & 0.197 & 0.905 & Valid \\
\hline & Butir 3 & 0.197 & 0.899 & Valid \\
\hline & Butir 4 & 0.197 & 0.860 & Valid \\
\hline & Butir 5 & 0.197 & 0.684 & Valid \\
\hline & Butir 6 & 0.197 & 0.907 & Valid \\
\hline & Butir 7 & 0.197 & 0.951 & Valid \\
\hline \multirow{7}{*}{$\begin{array}{c}\text { Lokasi } \\
\left(\mathrm{X}_{3}\right)\end{array}$} & Butir 1 & 0.197 & 0.892 & Valid \\
\hline & Butir 2 & 0.197 & 0.931 & Valid \\
\hline & Butir 3 & 0.197 & 0.694 & Valid \\
\hline & Butir 4 & 0.197 & 0.898 & Valid \\
\hline & Butir 5 & 0.197 & 0.678 & Valid \\
\hline & Butir 6 & 0.197 & 0.854 & Valid \\
\hline & Butir 7 & 0.197 & 0.888 & Valid \\
\hline \multirow{7}{*}{$\begin{array}{c}\text { Kepuasan } \\
\text { Konsumen } \\
\text { (Y) }\end{array}$} & Butir 1 & 0.197 & 0.767 & Valid \\
\hline & Butir 2 & 0.197 & 0.710 & Valid \\
\hline & Butir 3 & 0.197 & 0.821 & Valid \\
\hline & Butir 4 & 0.197 & 0.796 & Valid \\
\hline & Butir 5 & 0.197 & 0.776 & Valid \\
\hline & Butir 6 & 0.197 & 0.836 & Valid \\
\hline & Butir 7 & 0.197 & 0,857 & Vslid \\
\hline
\end{tabular}

Sumber : data primer yang diolah SPSS 22, 2020

Dari perhitungan diketahui nilai $r_{\text {hitung }}>$ dari $r_{\text {tabel }}$ dengan nilai standar 0,197 , jadi dapat sehingga dapat ditarik kesimpulan bahwa semua butir pertanyaan dalam variabel harga, lokasi, serta kualitas pelayanan, maupun kepuasan konsumen dinyatakan valid karena nilainya lebih dari nilai standar tabel. 


\section{Uji Reliabilitas}

Dari tabel hasil uji reliabilitas, terlihat bahwa nilai Cronbach Alpha masing-masing variabel yakni variabel harga, lokasi, serta kualitas pelayanan, maupun kepuasan konsumen $\geq 0,60$ maka hasil uji reliabilitas keseluruhan terhadap variabel hasilnya dinyatakan reliabel.

Tabel 2

Hasil Uji Reliabilitas

\begin{tabular}{|c|l|c|c|c|}
\hline No. & Variabel & $\begin{array}{c}\text { Cronbach } \\
\text { Alpha }\end{array}$ & $\mathbf{r}_{\text {tabel }}$ & Keterangan \\
\hline 1 & $\begin{array}{l}\text { Kualitas } \\
\text { Pelayanan }\end{array}$ & 0.960 & 0.197 & Reliabel \\
\hline 2 & Harga & 0.941 & 0.197 & Reliabel \\
\hline 3 & Lokasi & 0.924 & 0.197 & Reliabel \\
\hline 4 & $\begin{array}{l}\text { Kepuasan } \\
\text { Konsumen }\end{array}$ & 0.901 & 0,197 & Relisbel \\
\hline
\end{tabular}

Sumber : data primer yang diolah SPSS 22, 2020

\subsection{UJI ASUMSI KLASIK}

\section{1) Uji Normalitas}

Nilai Test Statistic Kolmogorov Smirnov adalah 0,053 dan signifikan pada 0,200 yakni > taraf signifikan 0,05 ini berarti bahwa distribusi data kepuasan konsumen adalah berdistribusi normal.

\section{2) Uji Multikolinearitas}

Hasil perhitungan uji multikolinearitas dalam penelitian ini menunjukkan model regresi tidak mengalami gejala multikolinearitas, sebab nilai tolerance lebih besar dari 0.10 dan nilai VIF nya kurang dari 10 .

\section{3) Uji Heterokedastisitas}

Hasil uji heterokedastisitas, membuktikan koefisien variabel kualitas pelayanan serta variabel lokasi bernilai signifikan, sedangkan variabel harga tidak signifikan. Jadi disimpulkan bahwa model regresi didalam penelitian ini tidak terdapat gejala heterokedastisitas.

\section{4) Uji Autokorelasi}

Dari hasil analisis output SPSS 22 menunjukkan besarnya nilai Durbin Watson sebesar 1.740, nilai dL sebesar 1.613 dan nilai dU sebesar 1.736 . Oleh karena itu nilai DW hitung $>\mathrm{dU}$ dengan menggunakan nilai signifikan 5\%, maka disimpulkan tidak terjadi autokorelasi antar residual.

\subsection{ANALISIS REGRESI BERGANDA}

Persamaan regresi yang diperoleh sebagai berikut :

$$
\begin{gathered}
Y=\alpha+b_{1} \cdot X_{1}+b_{2} \cdot X_{2}+b_{3} \cdot X_{3}+e \\
Y=4.475+0.126 X_{1}+0.348 X_{2}+0.374
\end{gathered}
$$

Dari persamaan diatas dapat diketahui bahwa :

a) Nilai koefisien regresi variabel kualitas pelayanan dengan nilai 0.126 bernilai positif. Maka apabila pemahaman pelanggan mengenai kualitas pelayanan naik, kepuasan konsumen juga akan meningkat. 
b) Nilai koefisien regresi variabel harga sebesar 0.348 bernilai positif. Maka apabila pemahaman konsumen mengenai harga naik, kepuasan konsumen juga akan meningkat.

c) Nilai koefisien regresi variabel lokasi sebesar 0.374 bernilai positif. Maka jika persepsi konsumen terhadap lokasi naik maka kepuasan konsumen juga akan meningkat.

\subsection{PENGUJIAN HIPOTESIS}

\section{1) Uji t}

Dari perhitungan uji t menunjukkan bahwa :

a) Nilai dari $t_{\text {hitung }}$ variabel kualitas pelayanan 1.602 lebih kecil dari nilai standar $\mathrm{t}_{\text {abel }} 1.984$ dan jika nilai sig 0.112 lebih besar dari standar sig. 0.05 berarti tidak bernilai signifikan. Jadi secara parsial variabel kualitas pelayanan tidak mempengaruhi variabel kepuasan konsumen. Ini berarti bahwa pelayanan yang diberikan oleh pemilik Paras Snack seperti tersedianya berbagai macam sampel snack, penanganan komplain,pelayanan yang sigap, penampilan yang menarik tidak berpengaruh terhadap kepuasan konsumen.

b) Nilai $t_{\text {hitung }}$ variabel harga 3.495 lebih besar dari nilai standar $\mathrm{t}_{\text {tabel }} 1.984$ dan nilai sig 0.001 lebih kecil dari standar sig. 0.05 yang berarti signifikan. Jadi secara parsial ada pengaruh signifikan variabel harga terhadap kepuasan konsumen. Sehingga harga yang murah sesuai daya beli serta sesuai dengan kualitas produk, serta adanya potongan harga dalam pembelian jumlah tertentu mempengaruhi kepuasan konsumen.

c) Nilai $t_{\text {hitung }}$ variabel lokasi 7.127 lebih besar dari nilai standar $t_{\text {abel }} 1.984$ dan nilai sig 0.000 lebih kecil dari nilai standar sig. 0.05 yang berarti signifikan. Maka variabel lokasi secara parsial mempunyai pengaruh signifikan terhadap kepuasan konsumen. Ini berarti lokasi yang mudah diakses, kondisi jalan yang bagus, mempunyai lahan parkir yang luas, lokasi yang aman, nyaman serta bersih berpengaruh terhadap kepuasan konsumen.

\section{2) Uji F}

Dari hasil uji $\mathrm{F}$, diperoleh nilai $\mathrm{F}_{\text {hitung }} 142.731$ yang mana nilai tersebut lebih besar dari nilai standart $F_{\text {tabel }} 2.70$ dengan tingkat sig. 0.000 lebih kecil dari nilai standar sig. 0.05. Jadi dapat ditarik kesimpulan terdapat pengaruh yang signifikan variabel independen terhadap variabel dependen secara simultan. Artinya kualitas pelayanan yang baik, harga sesuai dengan kempuan serta produk yang didapatkan konsumen dan lokasi yang aman, nyaman serta mudah dijangkau sangat berpengaruh terhadap kepuasan konsumen.

\section{3) Uji Koefisien Determinasi $\left(\mathbf{R}^{2}\right)$}

Dari tabel diatas bisa dilihat bahwa nilai Adjusted Rsquare adalah 0.811 sehingga variabel lokasi, kualitas pelayanan maupun harga, bersama-sama mampu menjelaskan variabel kepuasan konsumen sebesar $81.1 \%$, sedangkan 18,9\% dijelakan oleh variabel lain yang tidak diteliti misalnya diskon, kualitas produk, fasilitas dan lain sebagainya.

\section{KESIMPULAN DAN SARAN}

\subsection{Kesimpulan}

Dari hasil analisis yang diperoleh, kesimpulan sebagai berikut :

a) Secara parsial harga dan lokasi mempengaruhi kepuasan konsumen secara signifikan. Dengan diperolehnya nilai $\mathrm{t}_{\text {hitung }}$ variabel harga sebesar 3.495 lebih besar dari nilai standar $\mathrm{t}_{\text {abel }} 1.984$, dan nilai sig. 0.001 yang berarti lebih kecil dari nilai standar sig. 0.05 sehingga dapat dikatakan signifikan. Sedangkan nilai $\mathrm{t}_{\text {hitung }}$ variabel lokasi sebesar 7.127 lebih besar dari nilai standar $\mathrm{t}_{\text {tabel }}$ yakni 1.984, dan nilai signifikannya 0.000 yang berarti lebih kecil dari standar sig. 0.05, sehingga ada pengaruh yang signifikan ditunjukkan pada hasil uji t variabel harga dan lokasi.

b) Secara simultan variabel harga, lokasi, serta kualitas pelayanan, mempengaruhi kepuasan konsumen secara signifikan. Kesimpulan ini didasarkan pada perhitungan hasil uji $\mathrm{F}$, nilai $F_{\text {hitung }} 142,731$ lebih besar dari nilai $F_{\text {tabel }} 2.70$, dan tingkat signifikannya 0.000 lebih kecil dari nilai sig. 0.05 . 
c) Serta hasil uji determinasi $\left(\mathrm{R}^{2}\right)$ menunjukkan nilai Adjusted Rsquare adalah 0.811 ini berarti variabel harga, lokasi, serta kualitas pelayanan, bersama-sama mampu menjelaskan variabel kepuasan konsumen sebesar $81.1 \%$, sedangkan 18,9\% dijelakan oleh variabel lain yang tidak diteliti misalnya diskon, kualitas produk, fasilitas dan lain sebagainya.

\subsection{Saran}

Dari hasil penelitian yang dilakukan dengan kesimpulan diatas, adapun beberapa saran yang diharapkan dapat meningkatkan kepuasan konsumen antara lain sebagai berikut :

a. Diharapkan pelaku usaha Paras Snack dapat menjaga kualitas pelayanan dengan memberikan pelayanan terbaik sehingga meningkatkan minat pembelian untuk calon konsumen. Selain itu lokasi yang bersih, rapi serta tatanan ruang yang menarik menjadikan perhatian tersendiri pada para konsumen. Untuk memikat calon konsumen Paras Snack perlu sesekali memberikan promo potongan harga pada produk yang dijual, agar rasa keinginan membeli calon konsumen meningkat.

b. Kualitas pelayanan dan kepercayaan merupakan hal yang penting bagi konsumen, diharapkan pelaku usaha Paras Snack dapat mempertahankan kualitas pelayanannya dan meningkatkan kepercayaan konsumen dengan selalu menjaga kualitas produk yang sudah diketahui oleh sebagian masyarakat bahwa produk yang dijual Paras Snack adalah produk yang aman untuk dikonsumsi.

c. Harga produk Paras Snack perlu dipertahankan karena harga produk Paras Snack dapat dijangkau semua kalangan. Serta menambah inovasi-inovasi produk baru, untuk menambah daya tarik calon pembeli.

d. Lokasi strategis, mudah dijangkau, dan terdapat petunjuk arah untuk menuju lokasi, dapat meningkatkan minat beli konsumen. Lokasi yang aman nyaman dan bersih perlu dipertahankan untuk menjaga persepsi konsumen.

\section{DAFTAR PUSTAKA}

A. Kusumaningrostati and A. Mutasowifin, "Analisis Pengaruh Faktor-Faktor terhadap Income Smoothing dengan Gender sebagai Variabel Moderator pada Emiten Perbankan," J. Chem. Inf. Model., vol. 53, no. 9, pp. 1689-1699, 2017, doi: 10.1017/CBO9781107415324.004.

D. A. Sari, "Skripsi Mahasiswa Universitas Katolik Soegijapranata," vol. 1, no. 0, pp. 32-47, 2014.

I. A. P. Primadiawan, "PENGARUH KUALITAS PELAYANAN DAN HARGA TERHADAP KEPUASAN PELANGGAN BUS PO EKA Studi Kasus pada Pelanggan Bus PO EKA di Yogyakarta,” 2018.

K. Sulistiyani, "PENGARUH MOTIVASI DAN SELF EFFICACY TERHADAP KINERJA TENAGA KEPENDIDIKAN PADA SEKOLAH TINGGI DESAIN (STD) BALI."

L. B. dan H. B. Ronitua, Andreas, "PENGARUH BRAND IMAGE TERHADAP KEPUTUSAN PEMBELIAN AIR MINUM DALAM KEMASAN MEREK LE MINERALE," Desain Komun. Vis. Manaj. Desain dan Periklanan, vol. 14, no. 2, p. 116, 2016, doi: 10.25124/demandia.v1i02.276.

Mukhlis, M Aziz. 2019. "Pengaruh Lokasi Dan Kualitas Pelayanan Terhadap Kepuasan Pelanggan Pada Jasa Pengiriman J \& T Di Muara Bulian." Ekonomis: Journal of Economics and Business 3(1): 
Ningsih Diyan. 2013. "Analisis Pengaruh Pelayanan, Harga Dan Lokasi Terhadap Kepuasan Pelanggan Serta Dampaknya Pada Loyalitas Pelanggan Convenience Store 7-Eleven Uin Ciputat”. Universitas Islam Negeri Syarif Hidayatullah, Jakarta.

Nugroho, Marno dan Ratih Paramita. 2009. “Analisis Pengaruh Lokasi, Keanekaragaman Barang Terhadap Keputusan Berbelanja dan Loyalitas Konsumen di Carrefour Semarang”. Jurnal Ekonomi dan Bisnis. Januari, Vol. 10, No. 1

R. Hartanto, "Pengaruh Lokasi, Harga dan Fasilitas Terhadap Loyalitas Pelanggan Pada Doorsmeer Perdana Exspress Service Medan Universitas Sumatera Utara 6,” vol. 1, no. 2, pp. 6-38, 2001.

Sugiyono. 2011. Metode Penelitian Kuantitatif dan Kualitatif Research and Development. Alfabeta, Bandung.

Sugiyono. 2011. Statistika Untuk Penelitian. Alfabeta, Bandung.

Sugiyono. 2018. Metode Penelitian Kuantitatif. Alfabeta, Bandung.

Suminar, Ratna. 2017. "Pengaruh Kualitas Layanan Terhadap Kepuasan Konsumen Hypermarket." Jurnal Sekretari vol. 4 (1) : 28.

Supriyanto, "Analisis Pengaruh Kualitas Pelayanan, Harga, dan Fasilitas Terhadap Kepuasan Pasien Rawat Jalan di Rumah Sakit Kariadi Semarang,” Manajemen, vol. Volume 1 N, pp. 1-8, 2012, [Online]. Available: http://eprints.undip.ac.id/37113/.

Tjiptono, Fandy. 2014. Pemasaran Jasa - Prinsip, Penerapan dan Penelitian. Andi, Yogyakarta.

Tjiptono, Fandy. 2015. Strategi Pemasaran Edisi 4. Andi, Yogyakarta. 